\title{
Statistical Data About Risk Factors and Pregnancy Outcome of Placenta Previa
}

\author{
Kashami Arian (MD. PhD Candidate) \\ Troshani Amela (MD) \\ University Hospital of Obstetrics and Gynecology \\ "Koço Gliozheni", Tirana, Albania \\ Shabani Zamira (MD. PhD. Prof. Assoc) \\ University of Shkodra "Luigj Gurakuqi", \\ Faculty of Natural of Sciences, Shkoder, Albania
}

Doi: 10.19044/esj.2018.v14n15p27 URL:http://dx.doi.org/10.19044/esj.2018.v14n15p27

\begin{abstract}
Placenta previa is a placental location close to or over the internal cervical os. The aim of this study was to evaluate: risk factors, maternal and neonatal outcomes in patients with placenta previa. Material and methods: We conducted a retrospective cohort study of 38 women who have had a caesarean section for placenta previa at a tertiary referral University Hospital of Obstetrics and Gynecology "Koço Gliozheni" in Tirana, Albania. The period of this study was from January 2015 to March 2018. Maternal and neonatal data were obtained from medical records and the hospital database system. All cases of placenta previa were managed by medical team, obstetric consultants and all data were calculated with SPSS.20 program. Results: In total, 38 women with placenta previa were classified in three different types of placenta previa: Marginal placenta previa occurred in 16 women(42.1\%), Complete placenta previa occurred in 19 women $(50 \%)$ and with accreta placenta previa in 3 women(7.9\%). The mean age of mothers was 30,61 years old, mode $=35$, median $=30$ and Std. deviation $=4.641$ years. Conclusions: The prevalence rate of section caesarean and placenta previa is increased during the years. Several obstetrical factors have been found to be risk for placenta previa including: advancing maternal age, previous caesarean delivery, previous abortions, previous uterine surgery, multiparity, previous placenta previa, low socio-economic status, mother's cigarette smoking /alcohol use. Placenta previa is associated with an increase in preterm birth and neonatal and maternal outcome. Other complications of pregnancy can be associated with placenta previa, but the majority of women deliver healthy babies.
\end{abstract}


Keywords: Placenta previa, placenta accreta, maternal outcome, neonatal outcome

\section{Introduction}

Placenta previa (PP) is a placental location close to or over the internal cervical os. (Cunningham,2010). Placenta previa is the most common cause of painless bleeding in the later stages of pregnancy (after the 20th week), because the placenta is rich in blood vessels, if it is implanted near the outlet of the uterus, bleeding can occur when the cervix dilates or stretches. (James, 2007), (Milosevic,2009).

The exact etiology of placenta previa is unknown. However, it may be associated with abnormal vascularization. (Charles et al, 2014). The condition may be multifactorial and several obstetrical factors have been found to be risk for placenta previa including:

Uterine factors: Previous Caesarean section, Previous Abortion curettage (such as D\&C procedures for miscarriages or induced abortions) of the uterine cavity, or any type of surgery involving the uterus (Myomectomy), include scarring of the upper lining tissues of the uterus. (Ojha, 2012), (Gulrukh,2006), (Ananth, et al. 1997).

Placental factors: multiple gestation, mother's cigarette smoking/ alcohol use, and living at high altitude. So in these situations the placenta must grow larger to compensate for decreased function (lowered ability to deliver oxygen and/or nutrients). (Ananth, et al. 1997). It has also been observed that women carrying male fetuses are at slightly greater risk for placenta previa than are women carrying female fetuses. The risk of having placenta previa increases with: advanced maternal age, the number of previous deliveries, women with previous placenta previa. (Faiz, et al. 2003), (Ananth, et al.1996). Transvaginal ultrasonography is more accurate in diagnosing placenta previa than abdominal ultrasonography. However, with the technologic advances in ultrasonography, the diagnosis of placenta previa is commonly made earlier in pregnancy and then confirmation by magnetic resonance imaging (MRI). (Williams, et al. 1993), (Sherman, et al. 1992), (Warshak, 2006). 


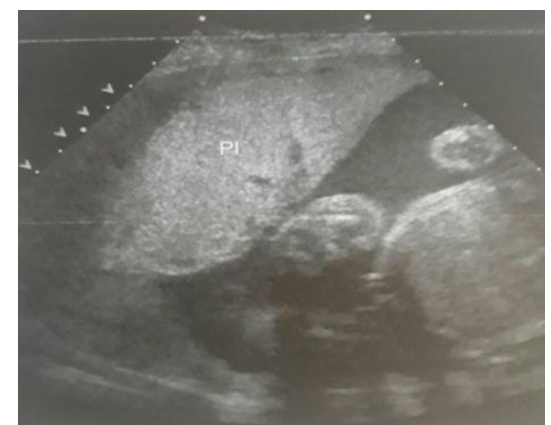

Fig. Nr. 1. Normal Placenta (Authors 2017)

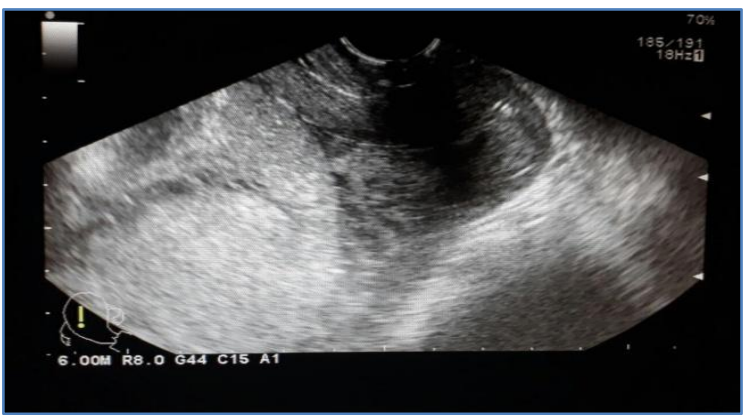

Fig. Nr. 2. Complete Placenta Previa (Authors 2017)

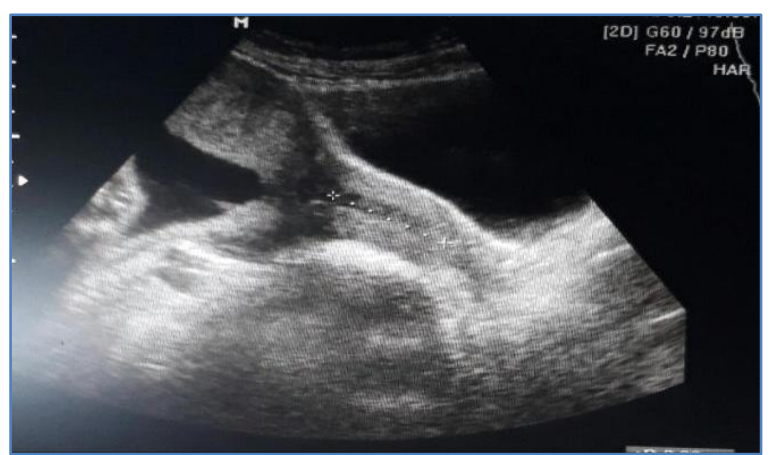

Fig. Nr. 3. Marginal Placenta Previa (Authors 2017)

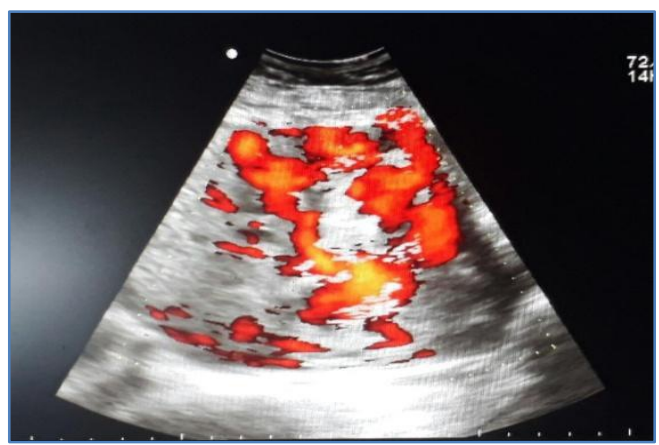

Fig. Nr. 4. Accreta Placenta Previa (Authors 2017) 
Historically, there have been three defined types of placenta previa: Complete placenta previa in which the placenta completely covers the internal os. Partial placenta previa in which the placenta partially covers the internal os. Marginal placenta previa in which the placenta is located adjacent to, but not covering, the internal os. (Smith, et al. 1997), (Creasy, et al.2014).

Placenta previa is associated with an increase in preterm birth and neonatal and maternal outcome. (Bhide,2003). Fetal intrauterine growth retardation (IUGR), Low birth weight $(<2500 \mathrm{~g}$ ), low Apgar score which needs admission in neonatal intensive care unit. Even neonatal death may occur. (Zlatnik, et al.2006). Maternal complications are: massive hemorrhage, emergency hysterectomy, multiple blood transfusions, urogenital injuries, sepsis, prolonged intensive care unit (ICU) and hospital stay. Management of placenta previa depends upon the extent and severity of bleeding, the gestational age and condition of the fetus, the position of the placenta and fetus, and whether the bleeding has stopped. (Eric. et al, 2001). Treatment of placenta previa involves bed rest and limitation of activity. Tocolytic medications, intravenous fluids, and blood transfusions may be required depending upon the severity of the condition. A Caesarean delivery is usually planned for women with placenta previa as soon as the baby can be safely delivered (typically after 36 weeks' gestation), although an emergency Caesarean delivery at any earlier gestational age may be necessary for heavy bleeding that cannot be stopped after treatment in the hospital.(Ara, et al, 2009). The risk of requiring hysterectomy following a caesarean delivery for patients with placenta previa (accreta if the placental tissue extends into the superficial layer of the myometrium) is increased.(Blackwell,2011), (Machado, 2011).

\section{Materials and methods}

We performed a retrospective cohort study, covering a period time from January 1,2015, to March 31, 2018, of women who have had a caesarean section for PP at a tertiary referral University Hospital of Obstetrics and Gynecology "Koço Gliozheni" in Tirana, Albania. Maternal and neonatal data were collected from the case notes (medical records and hospital database system) of women who were found to have PP on transabdominal or transvaginal ultrasound scanning and in whom the diagnosis was confirmed during Caesarean section. The ultrasound machine used was Aloka Echo Camera L. All ultrasound examinations were performed by an obstetrician. The transabdominal ultrasound examinations were performed with the bladder half-full and the transvaginal ultrasound examinations were performed with the bladder empty. The internal os was visualized, and the distance between the lower edge of the placenta and the internal os was measured.PP cases were 
managed by medical team, obstetric consultants. All data were calculated with SPSS. 20. Program.

Data were collected on patient age, parity, gestational age at time of caesarean delivery, history of previous PP, abortions, history of previous surgery intervention in uterine cavity, smoking cigarette and alcohol use, history of previous caesarean delivery, and degree of PP by ultrasound. The evaluation also included whether caesarean section was done electively or as an emergency, operative time. Neonatal evaluation included neonatal birth weight, Apgar score at 1 and 5 minutes, neonatal gender, position of fetus, generality admission to the neonatal intensive care unit, or any other complications.

\section{Results and discussions}

In total, 38 women with PP were classified:Marginal PP occurred in 16 women(42.1\%), Complete PP in 19 women(50\%) and 3 women(7.9\%) with Accreta PP. The mean age of mothers was 30.61 years old; mode $=35$; median $=30$ and Std. deviation $=4.641$ years. Our results showed that the overall prevalence rate of placenta previa was $1.6 / 1000$ birth life in $2015 ; 2.6 \%$ in 2016 and 4.2\%o in 2017. Also we can see that prevalence rate of section caesarean is increased during the years. Respectively this is $352.4 \%$ in 2015 ; $373.2 \%$ in 2016 and $403.5 \%$ in 2017.

Tab. Nr.1. Prevalence of S. Caesarean and Placenta Previa

\begin{tabular}{|cccccc|}
\hline Year & Nr. of birth & $\begin{array}{c}\text { Nr. } \\
\text { Sec.Caes }\end{array}$ & $\begin{array}{c}\text { Prevalence of } \\
\text { Sec. Caes }\end{array}$ & Nr. of P.P & $\begin{array}{c}\text { Prevalence of } \\
\text { 2015 }\end{array}$ \\
& 4279 & 1508 & $352,4 \%$.P & 7 & $1,6 \%$ \\
2016 & 4223 & 1576 & $373,2 \%$ o & 11 & $2,6 \% 0$ \\
2017 & 4037 & 1629 & $403,5 \%$ o & 17 & $4,2 \% 0$ \\
\hline
\end{tabular}

In Tab Nr. 2 we can see examples of situations like as living at a low socio-economic status. (57.9 \%) and mother's cigarette smoking/alcohol uses (39.5\%), increases risk for placenta previa.

Tab. Nr. 2. Mothers`demographic data and factors

\begin{tabular}{|c|c|c|c|c|c|}
\hline Soc-eco. Status & $\mathrm{Nr}$ & $\%$ & $\begin{array}{c}\text { Story of alcohol/ cigarette } \\
\text { uses }\end{array}$ & $\mathrm{Nr}$ & $\%$ \\
\hline Unemployed & 22 & 57.9 & No & 23 & 60.5 \\
\hline Employer & 16 & 42,1 & Yes & 15 & 39.5 \\
\hline Total & 38 & 100 & Total & 38 & 100 \\
\hline
\end{tabular}

As we can see at Tab Nr.3,4 that uterine factors can predispose to placenta previa include scarring of the upper lining tissues of the uterus. So placenta previa is more common among women who: Have had a baby $(50 \%$ second parity, $15.8 \%$ third parity, $10.5 \%$ multiparity), Previous caesarean 
delivery' including first subsequent pregnancy following a caesarean delivery( $42.1 \%$ after $1 \mathrm{~s} /$ caesarean, $5.3 \%$ after $2 \mathrm{~s}$ scaesarean, $5.3 \%$ after 3 s/caesarean), Abortions(dilatation and curettage) (65.8\% had 1 abortion, 5.3\% 2 abortions), had placenta previa with a previous pregnancy (15.8\%), previous uterine surgery $(15.8 \%)$, number of fetus ( $94.7 \%$ one fetus).

Tab. Nr. 3. Uterine factors

\begin{tabular}{|ccc|ccc|ccc|}
\hline Parity & $\mathrm{Nr}$ & $\%$ & $\begin{array}{c}\text { Previous } \\
\text { sec.caes }\end{array}$ & $\mathrm{Nr}$ & $\%$ & $\begin{array}{c}\text { Story of } \\
\text { abortion }\end{array}$ & $\mathrm{Nr}$ & $\%$ \\
0 & 3 & 7.9 & 0 & 18 & 47.4 & 0 & 12 & 28.9 \\
1 & 6 & 15.8 & 1 & 16 & 42.1 & 1 & 25 & 65.8 \\
2 & 19 & 50.0 & 2 & 2 & 5.3 & 2 & 2 & 5.3 \\
3 & 6 & 15.8 & 3 & 2 & 5.3 & & & \\
Multiparity & 4 & 10.5 & & & & & 38 & 100 \\
Total & 38 & 100 & & 38 & 100 & & 38 \\
\hline
\end{tabular}

The mean age of mothers that are with PP and their have had previous story with $\mathrm{PP}$ is 32.8 years old $(\mathrm{SD}=3,54$ and $\mathrm{SE}=1,4)$, but mothers that didn't have previous story of $\mathrm{PP}$, the mean age is 30.1 years old $(\mathrm{SD}=4.74$ and $\mathrm{SE}=0.83$ ).

Tab. Nr. 4. Uterine factors

\begin{tabular}{|c|c|c|c|c|c|c|c|c|}
\hline Nr. of fetus & $\mathrm{Nr}$ & $\%$ & $\begin{array}{l}\text { Previous } \\
\text { intervention } \\
\text { story }\end{array}$ & $\mathrm{Nr}$ & $\%$ & $\begin{array}{l}\text { Previous } \\
\text { PP story }\end{array}$ & $\mathrm{Nr}$ & $\%$ \\
\hline $\begin{array}{c}\text { Unic } \\
\text { (Singleton) }\end{array}$ & 36 & 94.7 & No & 32 & 84.2 & No & 32 & 84.2 \\
\hline $\begin{array}{c}\text { Multiple } \\
\text { Gestation(Twins) }\end{array}$ & 2 & 5.3 & Yes & 6 & 15.8 & Yes & 6 & 15.8 \\
\hline Total & 38 & 100 & Total & 38 & 100 & Total & 38 & 100 \\
\hline
\end{tabular}

As we can see at the Table Nr.5 that are three types of placenta previa (42.1\% Marginal, 50\% Complete and 7.9\% Accreta).However, maternal and fetal complications of placenta previa are well documented. Preterm birth is highly associated with placenta previa, with $57.9 \%$ of women delivering between 32-36 weeks and 26.3\% of them delivering > 36 weeks. Also from these 38 patients: $26(68.4 \%)$ delivered with emergency caesarean and 12 $(31.6 \%)$ were planned.

Tab. Nr. 5 Position of P.P, Gestational Age of delivery and mode of S.C

\begin{tabular}{|c|c|c|c|c|c|c|c|c|}
\hline $\begin{array}{c}\text { Position of } \\
\text { P.P }\end{array}$ & $\mathrm{Nr}$ & $\%$ & $\begin{array}{l}\text { G. Age of } \\
\text { Delivery }\end{array}$ & $\mathrm{Nr}$ & $\%$ & \multicolumn{3}{|c|}{ S.CNr\% } \\
\hline$\underset{P}{\text { Marginal P. }}$ & 16 & 42.1 & $\begin{array}{l}28-32 \\
\text { weeks }\end{array}$ & 6 & 15.8 & Emergency & 26 & 68.4 \\
\hline $\begin{array}{c}\text { Complete } \\
\text { P.P }\end{array}$ & 19 & 50.0 & $\begin{array}{l}32-36 \\
\text { weeks }\end{array}$ & 22 & 57.9 & Planned & 12 & 31.6 \\
\hline Accreta P.P & 3 & 7.9 & $>36$ weeks & 10 & 26.3 & Total & 38 & 100 \\
\hline Total & 38 & 100.0 & Total & 38 & 100 & & & \\
\hline
\end{tabular}


At the Table Nr.6 are summarized some of the neonatal complications of Placenta Previa: Abnormal fetal presentation $(31.6 \%$ breech, $28.9 \%$ transverse), Low birth weight (34.2\% 2000-2400 g) and some of them IUGR. It has also been observed that women carrying male fetuses $(73.7 \%)$ are at slightly greater risk for placenta previa than are women carrying female fetuses $(21.1 \%)$

Tab. Nr. 6.Position, gender and weight of fetus

\begin{tabular}{|ccc|ccc|ccc|}
\hline $\begin{array}{c}\text { Position of } \\
\text { fetus }\end{array}$ & $\mathrm{Nr}$ & $\%$ & $\begin{array}{c}\text { Fetus } \\
\text { gender }\end{array}$ & $\mathrm{Nr}$ & $\%$ & Weight of fetus & $\mathrm{Nr}$ & $\%$ \\
Cephalic & 13 & 34.2 & $\mathrm{M}$ & 28 & 73.7 & $1500-1900 \mathrm{gr}$ & 8 & 21.1 \\
Breech & 12 & 31.6 & $\mathrm{~F}$ & 8 & 21.1 & $2000-2400 \mathrm{~g}$ & 13 & 34.2 \\
Transverse & 11 & 28.9 & $\mathrm{M}-\mathrm{M}$ & 1 & 2.6 & $2500-2900 \mathrm{gr}$ & 10 & 26.3 \\
Twins & 2 & 5.3 & $\mathrm{~F}-\mathrm{M}$ & 1 & 2.6 & $\geq 3000 \mathrm{gr}$ & 7 & 18.4 \\
Total & 38 & 100 & Total & 38 & 100 & & & \\
\hline
\end{tabular}

Analyzing all cases with PP, using ANOVA test we didn't evidenced significant differences between weight of fetus, position of fetus position of PP, GA and mother's age. On the other hand we evidenced a very significant positive correlation between fetus weight and gestational age at the moment of birth. ( $\mathrm{p} \leq 0.001$, Pearson`s $\mathrm{R}=0.781)$. So increasing GA is increased also the weight of fetus. This is represented in the table nr. 7.

Tab. Nr.7. Correlation between GA and fetus weight

\begin{tabular}{|cccccc|}
\hline \multirow{2}{*}{ Weight } & & \multicolumn{3}{c}{ Gestational Age (GA) } & Total \\
& & $28-32$ & $32-36$ & $>36$ & \\
$1500-1900$ gr & Count & weeks & weeks & weeks & \\
& \% within GA & 100 & 2 & 0 & 8 \\
$2000-2400$ gr & Count & 0 & 12 & 0.0 & 21.1 \\
& \% within GA & 0 & 54.5 & 10 & 13 \\
$2500-2900$ gr & Count & 0 & 7 & 3 & 10 \\
& \% within GA & 0 & 31.8 & 30 & 26.3 \\
$>=3000$ gr & Count & 0 & 1 & 6 & 7 \\
& \% within GA & 0 & 4.5 & 60 & 18.4 \\
Total & Count & 6 & 22 & 10 & 38 \\
& \% within GA & 100 & 100 & 100 & 100 \\
\hline
\end{tabular}

Also we have evidenced that exists a very significant statistical difference between gestational age and delivery mode, (emergency caesarean section or planned caesarean section). So $\chi 2=21.84 ; \mathrm{df}=2 ; \mathrm{p} \leq 0,001$. (see tab. Nr. 8.) 
Tab. Nr. 8. Correlation between GA and mode of caesarean section

GA

28-32

weeks

Total

$32-36$

weeks

weeks
Count

$\%$ within $\mathrm{GA}$

$\%$ within Section Caesarean

$\%$ of Total

\begin{tabular}{cccc} 
Count & 6 & 0 & 6 \\
\% within GA & 100 & 0 & 100 \\
\% within Section Caesarean & 23.1 & 0 & 15.8 \\
\% of Total & 15.8 & 0 & 15.8 \\
Count & 19 & 3 & 22 \\
\% within GA & 86.4 & 13.6 & 100 \\
\% within Section Caesarean & 73.1 & 25 & 57.9 \\
\% of Total & 50 & 7.9 & 57.9 \\
Count & 1 & 9 & 10 \\
\% within GA & 10 & 90 & 100 \\
\% within Section Caesarean & 3.8 & 75 & 26.3 \\
\% of Total & 2.6 & 23.7 & 26.3 \\
Count & 26 & 12 & 38 \\
\% within GA & 68.4 & 31.6 & 100 \\
\% within Section Caesarean & 100 & 100 & 100 \\
\% of Total & 68.4 & 31.6 & 100 \\
\hline
\end{tabular}

\section{Conclusions}

- The prevalence rate of section caesarean and placenta previa is increased during the years 2015-2018. There are three types of placenta previa: $50 \%$ Complete, $42.1 \%$ Marginal and $7.9 \%$ Accreta.

- Several obstetrical factors have been found to be risk for placenta previa including: advancing maternal age (> 30 years), previous caesarean delivery (42.1\% after 1 s/caesarean), previous abortions $(65.8 \%$ had 1 abortion), previous uterine surgery (myomectomy), multiparity (50\% second parity), previous placenta previa, low socio-economic status (57.9\%), mother's cigarette smoking /alcohol use (39.5\%).

- Placenta previa is associated with an increase in preterm birth and neonatal and maternal outcome. Preterm birth with $57.9 \%$ of women delivering between 32-36 weeks, Abnormal fetal presentation (31.6\% breech, $28.9 \%$ transverse), Low birth weight (34.2\% 2000-2400 g) and some of them IUGR. So $68.4 \%$ of women delivered with emergency caesarean and $31.6 \%$ were planned. Also women carrying male fetuses $(73.7 \%)$ are at slightly greater risk for placenta previa. Other complications of pregnancy can be associated with placenta previa, but the majority of women deliver healthy babies. 


\section{References:}

1. Cunningham, Leveno, Bloom.(2010). Placenta Previa, Williams Obstetrics.; 23: 769-773.

2. James, Steer, Weiner. (2007). Placenta previa. High risk pregnancy. 4:1261-1266.

3. Milosevic, J., Lilic, V., Tasic, M., Radovic-Janosevic, D., Stefanovic, M., Antic, V. (2009).Placental complications after a previous cesarean section. Med Pregl. May-Jun. 62(5-6):212-6.

4. Charles, R.B., Beckmann, Frank W., Ling, William, N., Herbert, P., Casanova, R., Roger P. Smith., (2014). Obstetrics and Gynecology, Seventh Edition,; 164-166.

5. Ojha, N. (2012). Obstetric factors and pregnancy outcome in placenta previa. Journal of Institute of medicine. August; 34: 238 - 41

6. Gulrukh, Q. (2006). Obstetrics risk factors associated with major degree placenta previa development.JPMI.; Vol. 90 No. 3: 918 - 994.

7. Ananth, CV., Smulian, J., Vintzielos, A. (1997). The association of placenta previa with history of caesarean delivery and abortion; Ameta analysis. AmJobstGynaecol .; 177:1071-8.

8. Faiz, AS., Ananth, CV. (2003). Etiology and risk factors for placenta previa: an overview and meta analysis of observational studies. J Metern Fetal Neonatal Med. March; 13(3): 175 - 90.

9. Ananth, CV., Wilcox, AJ.,Savitz, DA., Bowes, WA. Jr., Luther, ER. (1996). Effect of maternal age and parity on the risk of uteroplacental bleeding disorders in pregnancy. Obstet Gynecol. Oct. 88(4 Pt 1):5116.

10. Williams, MA.,Mittendorf, R. (1993). Increasing maternal age as a determinant of placenta previa. More important than increasing parity? J Reprod Med. Jun. 38(6):425-8.

11. Sherman, SJ., Carlson, DE., Platt, LD., Medearis, AL. (1992). Transvaginal ultrasound: does it help in the diagnosis of placenta previa? Ultrasound Obstet Gynecol. Jul 1. 2(4):256-60

12. Warshak, CR., Eskander, R., Hull, AD., et al. (2006). Accuracy of ultrasonography and magnetic resonance imaging in the diagnosis of placenta accreta. Obstet Gynecol. Sep. 108(3 Pt 1):573-81

13. Smith, RS.,Lauria, MR., Comstock, CH., et al. (1997). Transvaginal ultrasonography for all placentas that appear to be low-lying or over the internal cervical os. Ultrasound Obstet Gynecol. Jan. 9(1):22-4.

14. Creasy, RK.,Resnik, R., Iams, J. , Lockwood, C., Moore, T., Greene, M. (2014).Placenta previa, placenta accreta, abruptio placentae, and vasa previa. Creasy and Resnik's Maternal-Fetal Medicine: Principles and Practice. 7th ed. Saunders: Philadelphia, PA; 732-742. 
15. Bhide, A., Prefumo, F., Moore, J., Hollis, B., Thilaganathan, B. (2003). Placental edge to internal os distance in the late third trimester and mode of delivery in placenta praevia. BJOG. Sep. 110(9):860-4.

16. Zlatnik, MG., Cheng, YW., Norton, ME., Thiet, MP., Caughey, AB.(2007). Placenta previa and the risk of preterm delivery. J Matern Fetal Neonatal Med. Oct. 20(10):719-23.

17. Eric, I., Archibong, El, S., Ahmad, M. (2001). Risk factors, Maternal and Neonatal outcome in major placenta previa: A prospective study. Annal of Saudi Medicine.; 21: No S 3 - 4.

18. Ara, A., Ara, J., Ahmad, A. (2009). Management and Maternal outcome in morbidly adherent placenta. Journal of surgery Pakistan. October - December; 14(4):166 - 169

19. Blackwell, SC. (2011). Timing of delivery for women with stable placenta previa. SeminPerinatol.. 35:249-51.

20. Machado, LS. (2011). Emergency peripartum hysterectomy: Incidence, indications, risk factors and outcome. N Am J Med Sci. Aug. 3(8):358-61. 